Please do not remove this page

RMIT

UNIVERSITY

\title{
Streaming services and the changing global geography of television
}

Lobato, Ramon

https://researchrepository.rmit.edu.au/esploro/outputs/9921860650601341/filesAndLinks?institution=61RMIT_INST\&index=null

Lobato, R. (2017). Streaming services and the changing global geography of television. In Handbook on Geographies of Technology (pp. 178-192). Edward Elgar Publishing Limited.

https://doi.org/10.4337/9781785361166.00020

Document Version: Submitted Version

Published Version: https://doi.org/10.4337/9781785361166.00020

Repository homepage: https://researchrepository.rmit.edu.au

(c) Barney Warf 2017

Downloaded On 2023/04/26 17:53:35 +1000

Please do not remove this page 
Thank you for downloading this document from the RMIT Research Repository.

The RMIT Research Repository is an open access database showcasing the research outputs of RMIT University researchers.

RMIT Research Repository: http://researchbank.rmit.edu.au/

\section{Citation:}

Lobato, R 2017, 'Streaming services and the changing global geography of television' in Barney Warf (ed.) Handbook on Geographies of Technology, Edward Elgar Publishing Limited, United Kingdom, pp. 178-192.

See this record in the RMIT Research Repository at:

https://researchbank.rmit.edu.au/view/rmit:42087

Version: Submitted Manuscript

Copyright Statement:

(C) Barney Warf 2017

\section{Link to Published Version:}

https://dx.doi.org/10.4337/9781785361166.00020 


\section{Streaming services and the changing global geography of television}

Ramon Lobato (Swinburne University of Technology)

rlobato@swin.edu.au

January 2016

\section{Pre-press version. Forthcoming in Handbook on Geographies of Technology, ed. Barney Warf, Cheltenham: Edward Elgar Publishing, 2016.}

On 6 January 2016, in a presentation at the Consumer Electronics Show in Las Vegas, Netflix CEO and co-founder Reed Hastings announced that his \$50-billion company had just become a global television service. With the exception of China, North Korea, Crimea, and Syria, Reed declared, Netflix was now unblocked and operating in every country of the world, ending years of patchy regional availability. 'Today,' said Hastings, 'you are witnessing the birth of a new global Internet TV network. With this launch, consumers around the world - from Singapore to St. Petersburg, from San Francisco to Sao Paulo - will be able to enjoy TV shows and movies simultaneously - no more waiting.' ${ }^{1}$

For anyone interested in the geography of television, this was a significant development. Ever since 2007, when Netflix unveiled a limited streaming service for its U.S. customers as a sideline to its mail-order DVD rental business, there has been much speculation about how the company would leverage the global distribution capacity of the Internet to bring over-the-top subscription television to international viewers. These rumours were confirmed when the Netflix streaming service began rolling out internationally, first to Canada in 2010, then to Latin America in 2011, to various European countries in 2012-2013, and to Australia, New Zealand and Japan in 2015. During these years the service also attracted many out-of-region users, who used VPNs (virtual private networks) and DNS (domain name system) proxies to covertly access the service before Netflix was available in their country.

What can the case of Netflix tell us about the changing geography of television? And what can existing scholarship on the geography of television tell us about Netflix? This chapter will draw out some of these connections between new and old forms of TV, from a media-geographical perspective. Streaming services are a hybrid phenomenon that brings together two historically distinct but now interrelated technological systems. Streaming uses the infrastructure of telecommunications and the internet, yet from the audience perspective, streaming is very much an extension of the television experience, and in terms of its commercial operations it relies upon 
the existing networks and relationships of TV production and distribution. So in streaming, two technological systems - television and telecommunications - now interact to produce a hybrid system with its own spatial logics.

Using Netflix as a case study², this chapter explores the geography of streaming services by focusing on three issues - infrastructure, distribution, and platform space. The aim here is not to provide a comprehensive account of these areas, each of which has its own extensive technical literature, but rather to explain how key concepts used with the interdisciplinary field of media geography can be productively revisited and rethought for the streaming age.

\section{The geographies of television}

Television as a medium has long been understood in terms of its capacity to compress, enchant, fill, expand and otherwise transform space. The fundamentally spatial power of the medium is referenced in the nineteenth-century usage of the precursor term 'tele-vision' - the transmission of images at a distance - which was understood as one of a suite of visionary spatial-extension technologies alongside telegraphy and telephony (Hay, 2004). ${ }^{3}$ Since the 1950 s, a rich tradition of critical writing has explored how television brings 'there' over 'here', realizes time-space compression, and fosters globalization - all fundamentally geographic concerns. From Marshall McLuhan's (1964) philosophy of electronic media and Raymond Williams' (1974) theory of mobile privatization, through to the 'situational geography' of communications theorist Joshua Meyrowitz (1985) and the influential writing of communications geographer Paul C Adams (1992), we now have many generative models for understanding television as a spatial medium.

In extending this line of research to streaming, there are two key issues to keep in mind. The first is that television is not a singular phenomenon but a bundle of different transmission technologies, industrial practices, textual forms and audience experiences. Each of these elements has its own spatial logic, so a meaningful analysis must be attuned to these specificities. This is a point made by Lisa Parks (2007: 114) who, in an essay on cable TV infrastructure, suggests that 'if television technology is a historically shifting form and set of practices, then it is necessary to consider more carefully how the medium's content and form change with different distribution systems'. For Parks, this task involves 'being able to understand and differentiate its distribution mode from others, whether these be broadcast, satellite, web, or wireless - systems that have themselves emerged in places in different ways' (ibid). It is therefore helpful to disaggregate TV into its constituent technologies for the purposes 
of analysis. Streaming has a different spatial logic from broadcast, which is different again from cable, satellite or mobile television.

The second issue is that, from an analytical perspective, any single form of television will have multiple geographies simultaneously. These would include, but are not limited to, an infrastructural geography of signal transmission and reception (e.g., Starks, 2013); an industrial geography of commercial relationships, alliances, and competition (Christophers, 2009); an experiential geography of domestic, public and mobile viewing (Spigel, 2004); a cultural geography involving traffic in images, ideas and representations (Morley and Robins, 1995); and so on. To fully understand television as a spatial medium, we must be attuned to the co-existence and interactions of these various dimensions. With these qualifications in mind, let us now explore what a media-geographical analysis of streaming services might reveal.

\section{Streaming infrastructure}

A useful point of departure is to consider the material properties of TV transmission technologies, in terms of their spatial reach, restrictions and dynamics. This is what we might call the infrastructural geography of television, and it is important because it determines the availability of TV culture for dispersed communities and viewers around the world.

As Parks reminds us, each TV technology has its own unique spatial logic. For example, the reach of broadcast TV is naturally limited by the finite reach of radio transmitters and their interaction with the topography of the landscape. In contrast, satellite has different characteristics: the footprint of a broad-beam satellite can cover up to $40 \%$ of the earth's surface, providing signals to an unlimited number of receivers, and overcoming terrestrial transmission obstacles such as mountain ranges and oceans. This entails a different kind of reception experience as well as a different political economy, characterised by high start-up costs and expensive hardware but formidable reach (including easy cross-border transmission). Attention to the specificity of TV infrastructure can help to explain the diverse evolution of industries and viewing cultures around the world - for example, why some countries including the United States, Netherlands and Singapore are predominantly cable TV markets, while in the Middle East and most of Europe satellite dominates.

Infrastructure also has more subtle effects on TV culture, as it feeds into the structure of programming and, by extension, audience reception. For example, satellite's numerous business- 
to-business applications have changed the industrial logic of television by accelerating the development of particular formats, genres and modes of address: direct transmission of programming between stations, from big-city TV studios to regional affiliates, led to the rise of national networks; the ability to beam content direct to international content partners created international made-for-TV spectacles (Our World, Live Aid) and global news networks (CNN); and the transnational footprints of commercial satellite operators have had profoundly disruptive and in some cases cosmopolitanizing effects on national broadcast cultures (Sakr, 2001; Parks, 2005).

Following this line of inquiry, let us now consider some of the infrastructural characteristics of internet television. Streaming platforms, as ‘over-the-top' video delivery services, are naturally reliant on telecommunications infrastructure - the vast networks of fibre and coaxial cable, copper telephone wires, and satellite data links that form the internet's underlying foundation. As internet geographers have shown (Zook 2006; Warf, 2013), these various layers of infrastructure are vital to how we experience the internet, if at all, and their spatial arrangement both reflects and entrenches longer histories of political-economic advantage and exclusion. The location and reach of ISPs; connection speeds and reliability; the variety of services available in particular locations; typical scenarios of access (wired connections, cybercafés or mobiles); regulatory control and censorship; the relations between communications infrastructure and urbanization these are all essentially spatial issues.

For streaming video applications, which require high download speeds, location is especially important. As an example, consider internet connection speeds. The minimum bandwidth required to use Netflix and other streaming services is $0.5 \mathrm{mbps}$ (megabits per second), and the recommended level is at least 3.0 mpbs. While Netflix automatically adjusts its resolution level upward or downward to match a customer's bandwidth, it cannot operate functionally below these thresholds. However, given that many of the world's largest emerging economies, including Indonesia, India, and the Philippines, have sub-3.0 average connection speeds (Akamai, 2015) and much slower average speeds and higher costs via mobile - this effectively puts Netflix offbounds for most of users in these countries. ${ }^{4}$

Taking this into account, one sees how the global expansion of premium streaming services is unlikely - at least in the short to medium term - to extend very far beyond the global urban middle-classes. In this sense, premium video streaming services are fundamentally different from basic internet protocols, such as email, which have greater flexibility and capacity to cater for mobile-first/mobile-only and low-bandwidth users. The need for credit card payments also 
restricts the diffusion of subscription services. ${ }^{5}$ So there is a spatial as well as an economic logic at work in determining the scale and extent of streaming take-up.

A second issue to consider when thinking about internet TV infrastructure is the location of backend services. For example, private data centers play a vital role in online video because they handle the traffic of major platforms. YouTube traffic relies on Google's global network of 14 data centers across the United States, Western Europe, South America and Asia (typically located in areas with cheap and reliable electricity supply). Another vital infrastructure element for streaming platforms are Content Delivery Networks (CDNs), third-party networks of distributed servers that reduce latency in streaming video transmission to make the experience faster and smoother (e.g., by caching popular video content in local servers closer to the end-user to reduce load times and buffering). CDNs such as Akamai and Amazon CloudFront have global networks of servers, concentrated mostly in the global North, which they use for local storage of popular content. In this sense they constitute an invisible but vital local delivery system for streaming infrastructure, one which has its own geography of location and service-provision.

Netflix is an interesting case here, because it has been developing a custom-built infrastructure tailored to its needs and using both in-house and third-party systems. In the past, Netflix used to maintain its own network of data centers but after a major crash in 2008 it has been progressively moving its services to the public cloud. Its last data center was closed a few years ago and Netflix now uses Amazon Web Services (AWS) instead. In contrast, the Netflix CDN strategy has been different: it used to partner commercial with Akamai, Limelight and Level 3 for CDN services, but since 2010 has been investing in its own CDN system called OpenConnect. So we can see here different tendencies of centralization and decentralization at the level of infrastructure, which are typical of the information technology industries.

For users, this network infrastructure is mostly invisible, or becomes visible only when it fails; and for this reason, following infrastructure theory, we can say that it is powerful precisely because of this invisibility (Star, 1999; Parks and Starosielski, 2015). Back-end infrastructure also inevitably has its own spatial logics of inclusion and exclusion. For example, we can expect Netflix's investments in its CDN infrastructure to primarily benefit established and emerging markets rather than peripheral areas with few current or potential subscribers. Studying these infrastructural issues reveals how not only the pleasures of streaming but also the irritation of buffering, drop-outs and pixellation are all spatially organized.

\section{Distribution and licensing}


A second strand of research on television geography concerns content distribution. Scholars working in this area have studied international programming flows - how various kinds of TV content reach audiences in different places, and the institutional structures that determine these flows. From this perspective, power is not just a question of transmission - the availability of a signal and receiving equipment - but also what is on the television (Christophers, 2009; Steemers, 2014). In other words, we are talking about cultural questions of diversity, accessibility and local representation.

Early work on international television distribution - its volume, intensity and political economy emphasised the one-way flow of content from the 'West to the Rest', in line with the dominant cultural imperialism thesis of the time (e.g. Boyd-Barrett, 1977). Later work has been more attuned to intra-regional and multi-directional flows, including regional TV markets within Latin America and Asia (Sinclair et al, 1995; Iwabuchi, 2002; Straubhaar, 2007). Research on the lessobvious forms of international distribution - such as the global trade in TV formats and franchises (e.g., Moran, 1998; Waisbord, 2014) - has added complexity to these debates by showing the importance of industries in Israel, Korea, the Netherlands and other second-tier exporter nations. Another line of research focuses on the location of television's commercial institutions, including distributors, program markets and trade fairs (Scott, 2004; Moran, 2009).

This body of work generates productive exchanges between media studies and geography. For example, Michael Curtin's diverse body of research into 'media capital', undertaken in various contexts including China and the US, investigates how geographies of production, talent mobility, distribution and regulation interact (e.g., Curtin, 2003, 2007). Likewise, the economic geographer Brett Christophers' work on the political and cultural economy of international television explicitly addresses the relationship between distribution, geography, technology and capital in order to explain how television and its underlying power-regimes are "accommodated and contested in materially geographic ways', and further, 'how programming itself materializes in place, and indeed how "place” materializes in programming' (Christophers, 2009: 3).

One aspect of streaming media that brings these concerns into sharp focus is digital content licensing. Streaming services partner with established TV producers and distributors to license their content and make it available on the platform. The terms of these licenses vary, and may include fixed or percentage-based payments, exclusive or non-exclusive terms, or advertising revenue splits. In most cases commercial content is licensed on a territory-by-territory rather than a global basis, in line with standard practice in international TV sales. From a geographic perspective, then, these deals are interesting because they highlight conflict between different 
scales and spatial logics of distribution. As Peter Yu has described, the internet, as a global, decentralized network, is structurally transnational in nature and frequently finds itself "in a collision course with the territoriality principle in intellectual property law" (Yu, 2015). In contrast, television's industrial practices are fundamentally shaped around territorial licensing and national copyright law, and streaming services must therefore be retrofitted with the locationaware capabilities required to enforce these boundaries, including geoblocking and geo-filtering (Trimble 2012; Yu 2015).

Current debates about Netflix licensing give an insight into these spatial conflicts. While Netflix produces its own 'Netflix originals' (House of Cards, Orange is the New Black), and licenses some titles on an exclusive, global basis (e.g., Making a Murderer), the majority of its content is licensed from the major U.S. entertainment conglomerates, including Disney, Time Warner, Comcast, Fox, Viacom, and CBS. For these conglomerates, Netflix is just one more buyer - albeit a large and formidable one - and should acquire content territory by territory in the usual fashion. So, while Netflix has been pushing hard for global licensing terms which would enable it to run a standardised global service, in practice it must usually negotiate the patchwork of territorial licensing deals like every other buyer, and is constrained by the deals done with other TV broadcasters who may have paid handsomely for exclusive rights in particular territories.

Netflix describes this situation as being a 'prisone[r] of territorial licensing' (USNetflix tweet, 6 January 2016). From the user perspective this means the Netflix streaming catalogue varies significantly from country, expanding and contracting and morphing when accessed from different parts of the world, with user access to overseas catalogues restricted through geoblocking. This is a source of controversy for its users, who increasingly expect global availability of their favourite content and find the territorial licensing system mystifying. This tension manifests itself in a range of everyday irritations, as when Netflix subscribers travelling abroad find that favourite series have disappeared from the catalogue, or when pre-release buzz about a show reaches fans in a territory where that content is not licensed, and thus unavailable.

These catalogue discrepancies constitute a geographic vector of difference, meaning that the experience of streaming is likely to vary from place to place. For example, in the United States the Netflix catalogue has around 7000 mostly American titles; in the United Kingdom, it is smaller but well stocked with American, British and international programming (including BBC shows); but in many of the peripheral territories where Netflix has just begun operating the choices are significantly reduced, and local-language subtitles are not available. In some countries, Netflix is even missing its signature shows such as House of Cards, having previously sold the rights to 
local TV channels (Sadaqat 2016). So this ostensibly global service is in reality very patchy and unevenly localized.

Thailand is one of the new Netflix territories that went live on 6 January 2016. So far, the reaction from Thais has been mixed (Bangkok Post and AP, 2016). Netflix Thailand has disappointed many because it has very few Thai titles available, and there is no Thai interface support, which means users must be able to read some English. Yet, due to the vagaries of international licensing, Netflix Thailand includes some premium content unavailable in the United States, such as The Godfather and Better Call Saul, which has pleased some viewers. There are also local regulatory priorities at work that will shape how the service is experienced within Thailand. At the time of writing, it is expected that Thai authorities will seek to censor or block some of Netflix's more racy content, which would likely fall foul of classification rules. ${ }^{6}$ Alternatively Netflix may seek to 'follow cinematic practice by pixelating smoking, drinking and bloody violence, as well as censor nude scenes' (Bangkok Post and AP, 2016, np). From this example we can see how an ostensibly global digital service is differentiated by multiple layers of industrial and regulatory contingency. From the end-user perspective, Netflix Thailand will be experienced as a rather different service from its other local iterations.

As global consumers become more familiar with streaming platforms, their awareness of the geographic disparities of content licensing and regulation grows. Through online forums, how-to sites and international catalog comparator services (such as Flixsearch), streaming fans around the world are becoming more savvy about the limited nature of many local catalogues and the better options elsewhere. This has led to widespread take-up of circumvention and unblocking services, many of which are custom-built for accessing international streaming sites (Lobato and Meese, 2016). In recent years an array of unblocking tools and workarounds - including hundreds of consumer-oriented VPN services (such as Private Internet Access, Hotspot Shield, Hide.Me, BlackVPN) and cheap DNS proxy services (Getflix, Unblock US) - have become popular with users as circumvention tools for accessing foreign Netflix sites, along with other kinds of geoblocked and government-censored content and services. While data on the use of circumvention services is unreliable, existing research paints a broad picture of substantial and growing global use (e.g., Roberts et al, 2010; Global Web Index, 2014).

As we can see from these examples, the distribution geographies of Netflix and other streaming services are complex and fast-changing. For our purposes there are two take-away lessons here. The first is that the cultural geography of video streaming is, for better or worse, inextricably linked to the economic geography of TV licensing and the legal institutions of territorial copyright. Any claim about the 'global' nature of internet video would therefore need to be tempered with a 
more sober analysis of how these various geographies intersect, and the social costs and benefits.

Second, in looking at the issue of geoblocking, circumvention and proxy/VPN use, we can observe different degrees of mobility on the part of viewers, with a small number able to easily cross digital borders and access programming meant for viewers in other territories, and a much larger number remaining effectively immobile. Given the current popularity of circumvention tools - which are by now established as an integral part of the internet TV landscape, and will remain popular with users so long as catalogue and pricing discrepancies between countries exist questions arise as to who can use these tools and who cannot. In other words, differential access to digital mobility needs to be understood as closely related to class, education, and technological competency. ${ }^{7}$ This dialectic between mobility and immobility is likely to become a more significant feature of television culture in the years ahead.

\section{Platform space}

So far we have explored two aspects of streaming, infrastructure and licensing, and discussed their spatial logics. We have also begun to consider differences and continuities vis-à-vis older forms of television. In so doing, we have been investigating foundational structures associated what Paul Adams (2007), in his taxonomy of communication geography, calls 'media-in-space' flows of content across space.

But there are other spatial dimensions of television, and of streaming, that we can analyze. One final dimension is what Adams calls 'space-in-media', or the way media experiences and technologies are themselves spatially organized. In Adams' words, 'communications are a kind of space - that is, a structured realm of interaction that both enables and constrains occupants in particular ways' (Adams 2010: 46), so it is helpful to consider how these communication and media-spaces are experienced from the user perspective, in terms of their internal spatiality. As anyone who has used Netflix, YouTube, or Hulu will know, the interfaces of streaming services are organized in particular ways, using various kinds of motifs and elements designed as navigational aids - playlists, charts, categories, 'verticals', 'horizontals', and so on. As such, these design features invite particular kinds of movement around the site and particular modes of searching, discovery and access. The resulting 'platform spaces' require analysis because they have an agency of their own. No media-space is neutral. It is therefore important to consider how today's streaming platforms are spatially structured, and to what effect. 
Various strands of thought in media scholarship are useful when considering this topic. Within television studies, for example, there is a long tradition of textual and ideological analysis which investigates how the experience of television viewing is organized around particular spaces of production, such as the TV studio, and their corresponding ways of seeing (think of the frontality of the sitcom set and the newsreader desk). As we move further into the digital age, these ways of experiencing televisual space are overlaid with the space of the platform - understood as a meta-structure that plays an active role in determining how we select, experience and understand the materials available on those services, which will in turn have their own internal spatial-aesthetic politics.

Geographers including Kitchin and Dodge (2011) and media scholars including José Van Dijck (2013) have written eloquently about the nature of digital platforms. Their work draws our attention to the structural capabilities and affordances of particular kinds of digital systems, determined at the level of code, and the way they shape user behaviour and subjectivity in subtle yet powerful ways. One of the recurring themes in this literature is the way that platforms work to classify and organize various kinds of content, making some things discoverable and other things obscure. As the cultural sociologist David Beer (2013: 62) writes in a critical synthesis of this literature, digital platforms present us with the need to consider 'how classificatory processes work to order culture on commercial, organisational, informal and everyday levels'. Central to these processes is algorithmic filtering, understood as a technique for shaping consumption in the context of complexity. As Beer writes, 'we can only imagine the density of algorithmic processes and the complex ways that they are now a part of the ordering, structuring and sorting of culture' (63).

Consider the example of YouTube. When we visit the site or use a YouTube mobile app, we are presented with a carefully structured screen-space that encourages certain kinds of interactions. YouTube's design has evolved over the years to become less like a traditional TV interface and more like a customisable, interactive database tailored to the interests of the individual user. Its purpose is to provide a constantly updated smorgasboard of content to keep users coming back to the site, paying attention, and generating advertising revenue. Across this platform YouTube and its parent company Google carefully prioritize certain kinds of strategically important partner content. So, while the platform is a space of interaction, it is also a commercial space in which every inch of screen real-estate is valuable. 

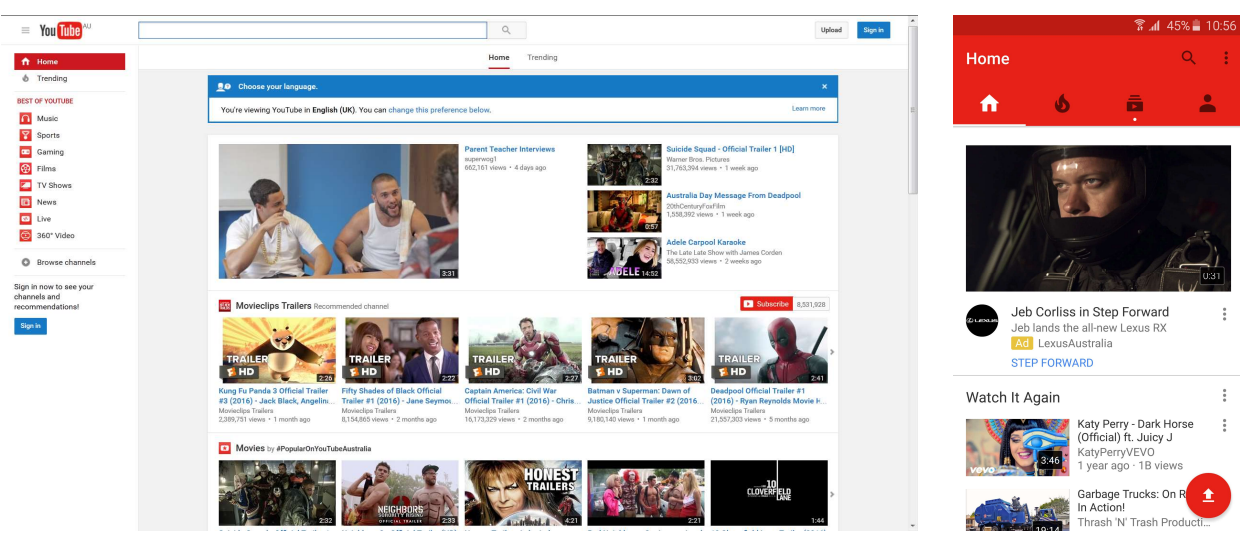

Figure 1: YouTube platform space, on PC and mobile, as of January 2016

To the left of the YouTube landing page, in PC view, we find links to our Library, Subscribed Channels, and various other sections. At the top, a search bar invites us to enter a query. The rest of the screen is filled with video links, organized into categories such as Recommended, Watch It Again, and Popular Right Now, and populated algorithmically with content according to our user history. These are arranged in horizontal layers which can be expanded or dismissed, so that the viewer can partially customize the space according to their own preferences. Because this content is all personally customized, no two unique users will experience the same YouTube front page. And like most streaming sites, YouTube has distinctly different interfaces for mobile, tablet, and computer views, which adds to the chameleonic nature of the platform.

Design features like this are significant from a media-geographic point of view because they involve sorting, rearrangement, and presentation of materials within the bounded but potentially infinite space of the browser window, tablet or mobile phone screen. While it has some parallels in media history, today's platform culture is in many respects unprecedented because of the level of personalization involved. Platform-space therefore represents something of an analytical challenge for researchers, and for the long and rich tradition of critical geographical research on cyberspace (e.g., Shields, 1996). Users do not navigate contemporary streaming services in the same way as they moved through early MUDs, Geocities sites, or Friendster. The norms, practices and design principles are constantly changing. We are in the realm of what Tarleton Gillespie (2010) calls 'the politics of platforms'. 


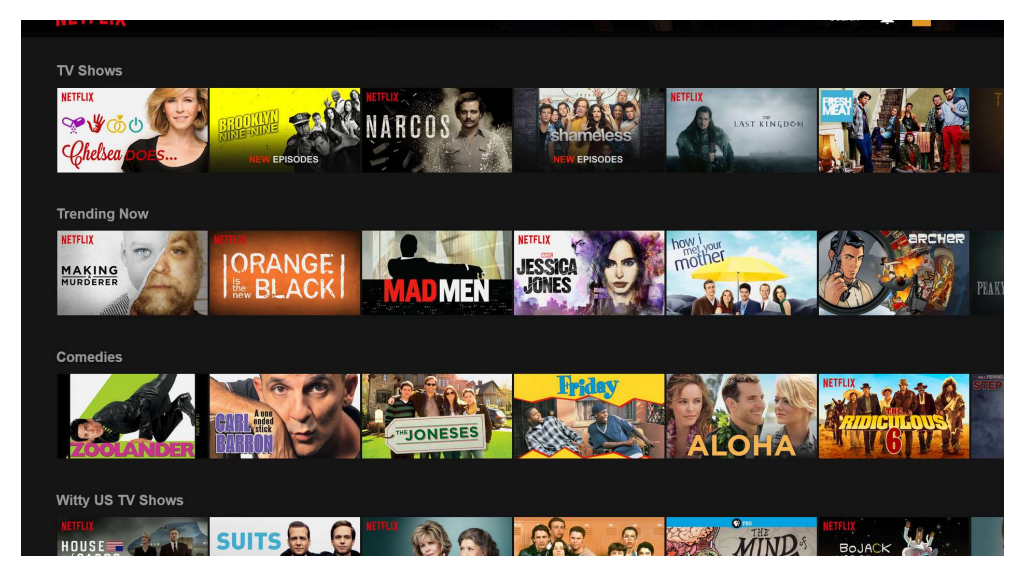

Figure 1: The Netflix front page, organized into horizontal strips (below the fold view)

Netflix again provides a rich case study to explore these issues, because its highly sophisticated platform design is so central to the user experience. Netflix is rightly famous for its personalization: every video selection that appears on the home-page is the result of intricate algorithmic calculation based on user-submitted data (movie ratings and viewing history), collaborative filtering (predictions based on other people's activities), and manual coding of films for all conceivable metadata points, from character types to endings (Madrigal, 2014). As Amanda Lotz (2014: 74-75) notes, the recommendation algorithm has a structural purpose in within the vast consumption-space of Netflix, in the sense it "provide[s] subscribers with a different paradigm for thinking about and organizing viewing behavior, and one that substantially challenges the long dominant, linear, “what's on” proposition'. As Lotz argues, 'Personalized queues in combination with recommendation algorithms [become] valuable tools for navigating an environment of post-network programming abundance' (79, emphasis added).

Drilling down into the Netflix interface, we can identify some design features that help to create this particular spatialized experience of abundance. Like YouTube, the Netflix interface is organized into horizontal strips of video links organized around particular categories, most of which are chosen on a user-customized basis from a list of thousands of potential genres, from broad categories (Romantic Comedies) through to hyper-specific micro-genres (Imaginative Time Travel Movies from the 1980s, Emotional Fight-the-System Documentaries) (Madrigal, 2014). This smorgasboard of content is arranged into movie-like reels of color that slide off the right side of the page, suggesting an infinite variety of choices. In this way the viewer is positioned as the sovereign navigator-user of an endless archive of screen content. Such design choices are carefully constructed to conceal limitations in what is in fact a finite Netflix catalogue, as discussed above. Crucially, all these choices are informed by location, based on user-entered customer profile data and the IP address of the user. From the kinds of categories promoted on the front page (telenovelas in Mexico, but not in Malta), through to the range of interface- 
languages, subtitles and soundtracks, location is an integral input into to the platform's algorithmic calculations and its appearance to the user.

One interesting aspect of the Netflix platform-space is how it frames the emergent practice of streaming by positioning it in relation to older screen technologies. Until 2015 the Netflix site had a light background and the video links were formatted in vertical, DVD cover-style boxes, so that the overall effect was reminiscent of a video store. Now, the background is dark - as in a movie theatre - and the DVD covers have been rearranged into a horizontal format suggesting frames on a celluloid film strip. This extensive and expensive site update seems designed not only to make the service as tablet-friendly as possible, hence the shift to horizontal format, but also to discursively reposition the site within the pantheon of older media technologies by moving the idea of Netflix away from video-store and DVD culture - surely a fading memory for most of its users - and realigning the service with that most resilient medium, cinema. Interestingly, the iconography of television is nowhere to be found in this platform-space: there are no screens, remote controls, advertisements, or schedules. Even though the idea of TV is central to Netflix's commercial ambitions - recall Hasting's boasting of Netflix as 'a new global Internet TV network' - and TV programming represents a massive proportion of the Netflix catalogue, the TV experience does not seem to be central to how Netflix wishes its users to imagine streaming. Perhaps this is due to the degraded nature of the televisual medium, and Netflix's related desire to market itself as a premium service. In any case, it is surely one of the ironies of internet television that its referent medium is being simultaneously effaced, reified, integrated and remediated through the emergence of streaming services.

\section{Conclusion}

In this chapter we have taken a spatial journey through Netflix, as a way into the wider field of television geography in the age of streaming. Starting with the infrastructural politics of the internet and ending with the pleasures of platform-space, we have approached the topic of streaming from a number of different angles that, it is hoped, together provide useful entry-points into what is undoubtedly a challenging and fast-changing topic. It is no accident that we have finished with the user experience, because it is where all the issues canvassed in this chapter become visible and tangible: the geography of internet infrastructure and connection speeds as the ultimate gatekeeper for access to video-on-demand; the variability of digital licensing, and its underlying economic and legal structures, as constraints on content availability; the drive towards personalization as a key logic of digital media (and the corresponding movement away 
from a monolithic idea of the global market to a model of located, niche audiences); the spatial organization and politics of platforms; the use of recommendation as a strategy for navigating the "environment of abundance"; and so on. As a key site for thinking about streaming culture, the case of Netflix touches on all of these fundamentally spatial issues.

I began this chapter by asking what streaming services can teach us about the geography of television, and what the geography of television can teach us about streaming. Perhaps the major lesson here is that streaming introduces another, spatially differentiated layer of inclusion and exclusion onto the existing palimpsest of television technologies. As we have seen from the various examples and controversies described above, complex questions of cultural geography are emerging, in which the boundaries of transmission, service-provision, distribution and regulation are mobile - but also incommensurate with one another. Internet geography, as the underlying foundation for streaming, exists alongside broadcast and pay TV but has distinct spatial logics. Overlaying this infrastructural geography of access is a political-economic geography of distribution and licensing, which has a separate logic again. And then on top of this there is the always-evolving interactive geography of the platform itself. Countries, regions, and individual users are differentially advantaged and disadvantaged across these various criteria. Some vectors of difference, such as territorial licensing, are contiguous with national borders while others, such as access to circumvention know-how (VPNs/proxies), are fundamentally transnational in nature. Each of these vectors of social, technological and infrastructural difference are vast areas of investigation in their own right, and further research is needed to understand their interaction. 


\section{ENDNOTES}

1 The full video of Hastings' address can be viewed at https://www.youtube.com/watch?v=15R3E6jsICA. 2 The Netflix model of browser-based subscription TV is just one kind of video streaming, which coexists with other subscription sites (Amazon Prime, Hulu Plus, Mubi), ad-supported free sites (YouTube, DailyMotion), catch-up TV (iPlayer, iView), and pirate streaming services (Popcorn Time and its various forks). Netflix is a unique case because it is the only subscription service with a truly global brand, and the only one to have become a cultural phenomenon in its own right.

${ }^{3}$ As Hay notes, "the idea of television emerged as a response to spatial questions and to modern ways of imagining and representing geography and mobility" (Hay 2004: 974).

4 The spatial distribution of Netflix subscribers is impossible to establish with certainty because Netflix does not release country-by-country subscriber numbers. But as of late 2015 , from the available information -- based on Netflix's disclosures about the ratio of US to international customers as of 2015 in various investor reports -- it appears Netflix is still a US-centric service in terms of its usage, with two thirds of its subscriber base located in the United States.

${ }^{5}$ Fidel Rodríguez (2016) notes that even though Netflix's much-discussed 2015 expansion to Cuba made it one of the first American companies to do business in the island in recent years, no Cubans can actually use the service because they do not have credit cards and Netflix does not accept local payment (not to mention the obvious income-level and internet speed disparities). Any discussion of international availability of Netflix, and of streaming in general, must therefore be textured with this kind of detail. ${ }^{6}$ Blocking of subscription streaming services by local authorities is already starting to happening in a number of countries, and will likely increase in the future. In Indonesia, for example, Netflix has been blocked for obscenity.

7 The appetite and know-how required for this mobility is itself unevenly distributed, but like other forms of mobility - such as air travel -- it is growing, and the barriers to access are decreasing as various userfriendly apps and free "geo-dodging" tools become available. The efficacy of these border-crossing workaround tools may wane as Netflix begins to crack down on "geo-dodging" 7 , as it has recently promised. 


\section{Reference list}

Adams, Paul C. (1992), 'Television as gathering place', Annals of the Association of American Geographers, 82 (1), pp. 117-135.

Adams, Paul C. (2007), Geographies of Media and Communication: A Critical Introduction. Chichester: Wiley-Blackwell. Adams, Paul C. (2010), 'A taxonomy for communication geography', Progress in Human Geography 35 (1): 37-57.

Akamai (2015), State of the Internet Report, Q3 2015, Cambridge: Akamai, accessed 10 January 2016 at http://stateoftheinternet.com

Beer, David (2013), Popular Culture and New Media: The Politics of Circulation, Basingstoke: Palgrave Macmillan.

Bangkok Post and AP (2016), 'After long wait, Netflix launches in Thailand, with caveats', Bangkok Post, 7 January, available at http://www.bangkokpost.com/news/general/818868/after-long-wait-netflix-launches-inthailand-with-caveats

Boyd-Barrett, Oliver (1977), 'Media imperialism: towards an international framework for the analysis of media systems', in James Curran, Michael Gurevitch and Janet Woollacott (eds), Mass Communication and Society, London: Edward Arnold, 116-135.

Christophers, Brett (2009), Envisioning Media Power: On Capital and Geographies of Television, Lanham: Rowman and Littlefield.

Curtin, Michael (2003), 'Media capital: towards the study of spatial flows', International Journal of Cultural Studies 6 (2): 202-228.

Curtin, Michael (2009), Playing to the World's Biggest Audience: The Globalization of Chinese Film and TV, Berkeley: University of California Press.

Gillespie, Tarleton (2010), 'The politics of “platforms”', New Media and Society 12 (3): 1-19.

Global Web Index (2014), 'The missing billion: how web analytics is wiping the emerging world off the map', industry whitepaper, London: Global Web Index.

Hay, James (2004), 'Television and geography', in Horace Newcomb (ed.), Encyclopedia of Television, second edition, London: Routledge, pp. 974-979.

Iwabuchi, Koichi (2002), Recentering Globalization: Popular Culture and Japanese Transnationalism, Durham: Duke University Press.

Kitchin, Rob and Martin Dodge (2011), Code/space: Software and Everyday Life, Cambridge, MA: MIT Press.

Lobato, Ramon and James Meese (eds) (2016), Geoblocking and Global Video Culture, Amsterdam: Institute of Network Cultures.

Lotz, Amanda (2014), The Television will be Revolutionized, second edition, New York: NYU Press.

McLuhan, Marshall (1964), Understanding Media: The Extensions of Man, New York: McGraw Hill.

Madrigal, Alexis (2014), 'How Netflix reverse engineered Hollywood', The Atlantic, 2 January 2014, available at http://www.theatlantic.com/technology/archive/2014/01/how-netflix-reverse-engineeredhollywood/282679/

Meyrowitz, Joshua (1985), No Sense of Place: The Impact of Electronic Media on Social Behavior, New York: Oxford University Press.

Moran, Albert (1998), Copycat Television: Globalisation, Program Formats and National Identity, Luton: University of Luton Press.

Moran, Albert (2009), TV Formats Worldwide: Localizing Global Programs, Bristol: Intellect Books.

Morley, David and Kevin Robins (1995), Spaces of Identity: Global Media, Electronic Landscapes, and Cultural Boundaries, London: Routledge.

Netflix, 'Netflix Is Now Available Around the World', press release, 6 January 2016, accessed 27 January 2016 at 
https://media.netflix.com/en/press-releases/netflix-is-now-available-around-the-world

Parks, Lisa (2005), Cultures in Orbit: Satellites and the Televisual, Durham: Duke University Press.

Parks, Lisa (2007), 'Where the cable ends', in Sarah Banet-Weiser, Cynthia Chris and Anthony Frietas (eds), Cable Visions: Television beyond Broadcasting, New York: New York University Press, pp. 103-126.

Parks, Lisa and Nicole Starosielski (2015), Signal Traffic: Critical Studies of Media Infrastructures, Urbana: University of Illinois Press.

Roberts, Hal, et al. (2010), 2010 Circumvention Tool Usage Report, Cambridge, MA: The Berkman Center for Internet \& Society.

Rodríguez, Fidel (2016), 'Cuba: Videos to the left - circumvention practices and audiovisual ecologies', in Ramon Lobato and James Meese (eds), Geoblocking and Global Video Culture, Amsterdam: Institute of Network Cultures, pp. 178-189.

Roxborough, Scott (2015), 'Netflix's Ted Sarandos Heckled at Cannes: "You Will Destroy the Film Ecosystem in Europe"', Hollywood Reporter, 15 May 2015, http://www.hollywoodreporter.com/news/cannes-2015-netflixsted-sarandos-795857.

Sadaqat, Rohma (2016), 'Patience! You're gonna get more titles in UAE: Netflix', Khaleej Times, 13 January 2016, accessed 29 January 2016 at http://www.khaleejtimes.com/business/local/patience-youre-gonna-get-moretitles-in-uae-netflix

Sakr, Naomi (2001), Satellite Realms: Transnational Television, Globalization and the Middle East, London: I.B. Tauris. Scott, Allen J. (2004), On Hollywood: The Place, The Industry, Princeton \& Oxford: Princeton University Press.

Shields, Rob, ed. (1996) Cultures of Internet: Virtual Spaces, Real Histories, Living Bodies, London: Sage.

Sinclair, John, Liz Jacka, and Stuart Cunningham (eds) (1995), New Patterns in Global Television: Peripheral Vision, New York: Oxford University Press.

Spigel, Lynn (1992), Make Room for TV: Television and the Family Ideal in Postwar America, Chicago: University of Chicago Press.

Star, Susan Leigh (1999), 'The Ethnography of Infrastructure', American Behavioral Scientist, 43 (3): 377-391.

Starks, Michael (2013), The Digital Television Revolution: Origins to Outcomes, Basingstoke: Palgrave.

Steemers, Jeanette (2014), 'Selling television: addressing transformations in the international distribution of television content', Media Industries Journal 1 (1), pp. 44-49.

Straubhaar, Joseph (2007), World Television: From Global to Local, Los Angeles: Sage.

Trimble, Marketa (2012), 'The future of cybertravel: legal implications of the evasion of geolocation', Fordham Intellectual Property, Media \& Entertainment Law Journal, 22 (3): 567-657.

van Dijck, José (2013), The Culture of Connectivity: A Critical History of Social Media, New York: Oxford University Press.

Waisbord, Silvio (2004), 'McTV: understanding the global popularity of television formats', Television and New Media 5 (4): 359-383.

Warf, Barney (2013), Global Geographies of the Internet, Dordecht: Springer.

Williams, Raymond (1974), Television: Technology and Cultural Form, London: Fontana.

Yu, Peter K. (2015), 'Towards the seamless global distribution of cloud content', in Anne S.Y. Cheung and Rolf H. Weber (eds), Privacy and Legal Issues in Cloud Computing, Cheltenham, UK, and Northampton, MA: Edward Elgar, pp. 180-213.

Zook, Matthew (2006), 'The Geographies of the Internet', Annual Review of Information Science and Technology 40 (1): 53-78. 